\section{Myeloma's IRF4 addiction}

\section{By Brian Moy, Staff Writer}

A paper published in Nature suggests that inhibiting interferon regulatory factor 4 could be useful for treating multiple myeloma (MM). Although the study identified the transcription factor as a regulator of several gene pathways central to myeloma cell survival, a challenge will be finding a way to target it without disrupting its role in lymphocyte activation.

The study, led by researchers at NIH's National Cancer Institute (NCI), used a loss-of-function genetic screen in which small hairpin RNAs were screened for their ability to block cancer cell proliferation and survival. The screen found that myeloma cells receiving an shRNA targeting the coding region of interferon regulatory factor 4 (IRF4) were depleted from cultures by up to eightfold compared with that of cells receiving different shRNAs.

Expression of IRF4 is highly restricted to B cells, plasma cells and mature $\mathrm{T}$ cells.

In myeloma cells, a $50 \%$ reduction in IRF4 gene expression by shRNA knockout was sufficient to kill the cell lines. IRF4 depletion was toxic to all myeloma cell lines regardless of molecular subtype. ${ }^{1}$

Leif Bergsagel, a professor of medicine at the Mayo Clinic, said "the significance of the paper is that it shows that IRF4 is a master molecular switch that controls cancer cell fates."

Louis Staudt, principal investigator and corresponding author of the Nature paper, agreed. He told SciBX that because dependency on IRF4 was not contingent on the genetic subtype of MM, IRF4 could indeed be a viable drug target for treating all types of myeloma.

Staudt is chief of the Lymphoid Malignancies Section in the metabolism branch of the Center for Cancer Research at the NCI.

Ongoing studies by Staudt and colleagues are investigating the molecular pathways underlying IRF4 activity and its role in regulating myeloma cell proliferation and survival.

Andreas Neubauer, a professor of medicine at the University of Marburg, said that "a further understanding of the biochemical and molecular pathways that IRF4 is involved in would result in significant therapeutic progress" for MM. However, he added that previous research has indicated that IRF4 may also be a tumor suppressor in myeloid neoplasms such as chronic myelogenous leukemia (CML) and acute myelogenous leukemia (AML). ${ }^{2}$

As a result, Neubauer said, "side effects of broadly inhibiting IRF4 should be carefully investigated."

\section{Targeting factor}

Because transcription factors such as IRF4 function in the nucleus and interact with other proteins and DNA in ways that are not easily amenable to drug targeting, a better strategy may be to look for more easily druggable targets in the IRF4 pathway.

"We need to know what turns IRF4 on in both normal cells and cancer cells," Bergsagel said. "If we can identify a signaling pathway that is turning IRF4 expression on, we can target its upstream effectors as a therapeutic approach."

Jordan Fridman, director of pharmacology at Incyte Corp., said the opposite approach-hitting downstream targets of IRF4 such as IL-6might work. He added that "Janus-associated kinases against IL-6, which have been linked to the proliferation and growth of multiple myeloma cells for a number of years, could be useful for treating disease."

Incyte's INCB18424, a Janus-associated kinase (JAK) inhibitor, is in Phase II testing to treat relapsed or refractory MM.

Fridman also told SciBX that because IRF4 is needed for a viable immune system, "you don't want to inhibit it all the way and all the time, as complete knockdown would ablate lymphocyte development and function."

Staudt agreed. "Full inhibition of IRF4 might lead to problems with adaptive immunity," he said, suggesting partial inhibition might circumvent such issues.

John Shaughnessy, a professor of medicine and chief of the Division of Basic Sciences at the Myeloma Institute for Research and Therapy at the University of Arkansas for Medical Sciences, told SciBX that "there should be a detailed expansion of our knowledge of the IRF4 signaling network in order to identify other potential therapeutic targets that might be more tractable and supplant or complement IRF4 ablation."

Shaughnessy added that "if the focus is to remain on the use of shRNAs, further development of shRNA delivery systems will be required" because myeloma cells are difficult to transduce with naked DNA or shRNA. "Even in cell culture, the efficiency of getting shRNA into each cell is difficult," he said.

Shaughnessy suggested that adenovirus vectors or liposomal delivery systems might be options for delivery in humans.

Before that, Shaughnessy said, "since all of the current studies were done in vitro, the shRNA needs to be shown to be effective in a preclinical in vivo model of multiple myeloma."

According to Staudt, the IRF4 findings described in the paper have not been patented.

\section{REFERENCES}

1. Shaffer, A. et al. Nature; published online June 22, 2008;

doi:10.1038/nature07064

Contact: Louis Staudt, National Cancer Institute, Bethesda, Md. e-mail: Istaudt@mail.nih.gov

2. Schmidt, M. et al. J. Clin. Oncol. 18, 3331-3338 (2000)

COMPANIES AND INSTITUTIONS MENTIONED

Incyte Corp. (NASDAQ:INCY), Wilmington, Del.

Mayo Clinic, Rochester, Minn.

National Cancer Institute, Bethesda, Md.

National Institutes of Health, Bethesda, Md.

University of Arkansas for Medical Sciences, Little Rock, Ark.

University of Marburg, Marburg, Germany 